\title{
Colaboração em Atividade Online de Formação de Professores de Matemática
}

\author{
Collaboration in Online Activity of Mathematics Teacher Trainning
}

\author{
Roberto Mariano de Araújo Filho \\ Programa de Pós-graduação em Edu- \\ cação Matemática e Tecnológica - \\ UFPE \\ Av. Acadêmico Hélio Ramos, s/n \\ CDU - Recife-PE \\ roberto.m.a.f@gmail.com
}

\author{
Verônica Gitirana \\ Programa de Pós-graduação em Edu- \\ cação Matemática e Tecnológica - \\ UFPE \\ Av. Acadêmico Hélio Ramos, s/n \\ CDU - Recife-PE \\ veronica.gitirana@gmail.com
}

\author{
Celso Gonçalves \\ Bacharelado em Psicologia - UNI- \\ TRI \\ Av. Nicomedes Alves dos Santos, \\ 4545 - Gávea - Uberlândia - MG \\ celsoandre2002@yahoo.com.br
}

\begin{abstract}
Resumo Este artigo discute elementos da colaboração presentes na atividade de grupo de licenciandos em Matemática para a elaboração de uma aula sobre funções em um ambiente colaborativo online. Grupo este selecionado, dentre três outros da pesquisa de mestrado, pelo destaque quanto à atividade colaborativa. Este artigo discute os fatores que foram determinantes na colaboração do grupo. O quadro teórico compõe-se da Aprendizagem Colaborativa Suportada por Computador CSCL, elencando o modelo de análise colaborativo, o script e o seu papel na sessão. Na metodologia, trazemos uma descrição do sujeitos, do ambiente estruturado e da coleta dos dados. Os resultados apontam que a autonomia dos sujeitos na busca de fontes externas ao ambiente foi determinante no processo de colaboração.
\end{abstract}

Palavras-Chave: aprendizagem colaborativa, função, formação de professor, educação online, software educacional, modelagem

\begin{abstract}
This paper discusses aspects of collaboration present in the activity of a group of students, from mathematics teachers undergraduation course, to develop a class about function in an online collaborative environment. This group was selected to be addressed here, among other three groups, by the prominent role collaborative aspects took in their activity. Therefore, this paper the factors that were crucial on this group collaboration. The theoretical framework comprised by Computer Supported Collaborative Learning CSCL, highlighting analysis of the collaborative model, the script and its role in the session. From the methodology, we bring a description of the students, the environment built for the study and data collection. The results reveal that students' autonomy in external sources searching was determinant for collaboration.
\end{abstract}

Keywords: Collaborative learning, function, teacher training, online education, educational software, modelling 



\section{Introdução}

Com o avanço tecnológico presente nos dias de hoje, muitos artefatos estão disponíveis para auxiliar as pessoas de diversas maneiras: a comunicação em rede, os dispositivos de localização e também os recursos tecnológicos com fins educacionais, seja de aprendizagem ou de formação.

A nossa pesquisa [1] tem o foco na aprendizagem colaborativa por meio de ambientes online que permitem a comunicação à distância. Acreditamos que a colaboração contribuí na construção de conceitos coletivamente e individualmente.

Percebemos que as pesquisas em torno da aprendizagem colaborativa com suporte computacional estão crescendo, mas ainda há muito a investigar. Alguns dos objetos de investigação na aprendizagem colaborativa estão em torno de como os sujeitos interagem em um ambiente à distância, a forma de organização dos grupos online, os entraves tecnológicos envolvidos neste processo e até que ponto estes entraves influenciam na construção dos conceitos.

As limitações dos ambientes colaborativos com suporte computacional ficam evidentes quando envolvem alguma atividade matemática. A mobilização de representações próprias da Matemática têm se mostrado um fator catalizador dessas limitações, sendo assim, a necessidade de investigar ambientes que suportem essas atividades é extremamente necessária.

Nesse sentido nos despertou o interesse de investigar as potencialidades e limitações desse modelo de aprendizagem ligado a um conceito matemático. Escolhemos explorar as funções afim e quadrática, por meio da modelagem matemática.

Trazemos neste artigo um recorte de uma dissertação de mestrado, que teve como objetivo analisar a aprendizagem colaborativa suportada por computador no contexto da formação do professor de Matemática quando ao uso de modelagem para o ensino de funções.

A atividade proposta consistiu na elaboração de uma aula planejada de forma colaborativa online, para o ensino de funções. Nesta atividade trabalharam três grupos: alfa, beta e gama. Os resultados da pesquisa mostraram que o grupo Beta colaborou em todos os pontos da sessão. Sendo assim, nosso objetivo neste artigo é evidenciar os aspectos que levaram o grupo a colaborar mais, considerando os recursos, as conversas entre os sujeitos e as ações mobilizadas durante a realização da atividade.

$\mathrm{O}$ artigo traz os aspectos relevantes sobre aprendiza- gem colaborativa que são necessários na compreensão da análise dos dados. Estruturamos o artigo em quatro sessões: primeiro trazemos os aspectos da aprendizagem colaborativa com suporte computacional com o modelo de análise utilizado, em seguida destacamos a metodologia da pesquisa evidenciando a estrutura do ambiente montado e uma descrição da coleta dos dados. Na terceira, trazemos a análise dos dados a partir dos aspectos da colaboração e dos entraves encontrados pelo grupo Beta $\mathrm{e}$ por fim, as conclusões, mostrando os pontos que levaram o grupo a colaborar.

\section{Aprendizagem Colaborativa Supor- tada por Computador (CSCL)}

A Aprendizagem Colaborativa Suportada por Computador (CSCL - Computer-Supported Colaborative Learning) é definida como uma ciência da aprendizagem que investiga como o sujeito aprende com o auxílio do computador [2]. No entanto, a complexidade da CSCL permeia várias situações da aprendizagem mediada por computador, como a interação dos sujeitos, o ambiente de comunicação e as formas da colaboração.

A CSCL investiga a colaboração entre indivíduos que fazem uso do computador para interagir, na qual a comunicação pode ser síncrona ou assíncrona. Além disso, um ponto central da investigação na CSCL é a colaboração versus cooperação. Estes dois conceitos apresentam definições muito semelhantes no senso comum, mas para CSCL, eles divergem como afirmam Stahl et al [2] (p. 411):

$\mathrm{Na}$ cooperação, a aprendizagem é realizada por indivíduos que contribuem com seus resultados individuais e apresentam a sua agregação como o produto do grupo [...] na colaboração os indivíduos estão envolvidos como membros do grupo, mas as atividades nas quais eles estão engajados não são atividades de aprendizagem individual, mas sim nas interações do grupo, como negociação e compartilhamento. Os participantes não se isolam para realizar atividades individualmente, mas mantêm-se engajados em uma tarefa compartilhada que é construída e mantida pelo e para o grupo como tal.

Segundo Stahl [3], a CSCL considera o grupo como uma unidade, no entanto, a individualidade do sujeito está intimamente ligada às suas ações dentro do grupo. $\mathrm{O}$ autor considera que investigar o pensamento do indivíduo como reflexo de suas ações no grupo, ainda, é objeto de investigação dos pesquisadores, pois o individual e o 
coletivo estão imbricados nas interações colaborativas.

Na seção seguinte, discutiremos o modelo de análise que utilizamos para nossa pesquisa. Discutiremos os aspectos mais relevantes do modelo, que nos conduziu a análise do grupo investigado.

\subsection{O modelo de análise de Baker}

Para analisar a interação entre os sujeitos utilizamos o modelo de análise de Baker. Este modelo concentra três dimensões fundamentais, que nos auxiliaram na análise das interações estruturando as conversas ocorridas durante a atividade. A estrutura organizada do modelo nos permitiu observar algumas subdimensões, as quais classificamos as interações no intuito de identificar a cooperação e a colaboração.

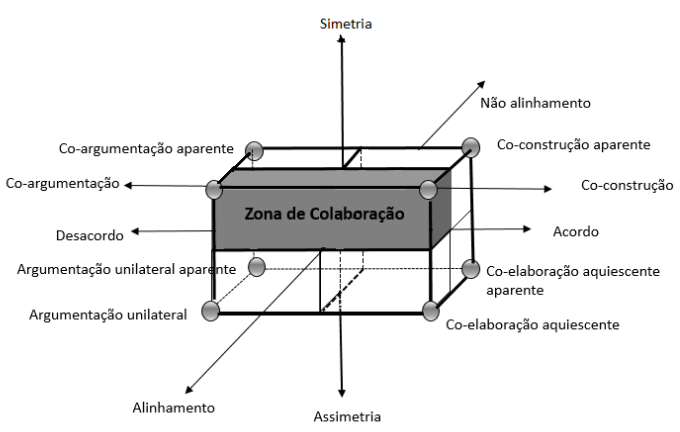

Figura 1: Modelo de análise de Baker (Fonte: adaptado de [4], p.592)

Observe na figura 1 que o autor traz as dimensões simetria, acordo e alinhamento - e as oito subdimensões de análise. Vamos definir de acordo com Baker [4], como as dimensões organizam as estrutura das interações:

Simetria: a dimensão simetria se refere aos papéis assumidos pelos sujeitos no processo de interação. $\mathrm{O}$ autor classifica estes papeis em propositor e reator, onde o propositor é aquele que se coloca como questionador e o reator dá um feedback para as questões. A simetria ocorre quando estes papéis se alternam entre os membros da sessão, caso contrário, dizemos que a conversa é assimétrica.

Acordo: o acordo se refere aos feedbacks do reator para o propositor. O acordo ocorre se o reator concorda com o propositor, caso contrário, dizemos que há desacordo.

Alinhamento: o alinhamento é a dimensão que observa o engajamento dos participantes no grupo. $\mathrm{O}$ alinhamento ocorre se os participantes estão no mesmo foco, discutindo os mesmos aspectos, caso contrário, os participantes não estão alinhados. Baker afirma que os sujeitos para estarem alinhados devem estar na mesma base semântica, isto é, dentro do mesmo contexto na discussão.
Ao organizar a conversa nestas três dimensões, podemos partir para as subdimensões, nas quais identificamos a cooperação ou a colaboração entre os sujeitos. Observe no quadro 1, como classificam-se as interações por meio das subdimensões do modelo.

\begin{tabular}{|c|c|c|}
\hline Subdimensão & Interação & Classificação \\
\hline Co-construção & $\begin{array}{l}\text { Simétrica, em acordo e } \\
\text { alinhada }\end{array}$ & Colaboração \\
\hline Co-argumentação & $\begin{array}{l}\text { Simétrica, em desacor- } \\
\text { do e alinhada }\end{array}$ & Colaboração \\
\hline $\begin{array}{l}\text { Co-construção } \\
\text { aparente }\end{array}$ & $\begin{array}{l}\text { Simétrica, em acordo e } \\
\text { não alinhado }\end{array}$ & Cooperação \\
\hline $\begin{array}{l}\text { Co-argumentação } \\
\text { aparente }\end{array}$ & $\begin{array}{l}\text { Simétrico, em desacor- } \\
\text { do e não alinhado }\end{array}$ & Cooperação \\
\hline $\begin{array}{l}\text { Co-elaboração } \\
\text { aquiescente }\end{array}$ & $\begin{array}{l}\text { Assimétricos, alinhados } \\
\text { e em acordo }\end{array}$ & Colaboração \\
\hline $\begin{array}{l}\text { Co-elaboração } \\
\text { aquiescente aparente }\end{array}$ & $\begin{array}{l}\text { Assimétricos, em } \\
\text { acordo e não alinhados }\end{array}$ & Cooperação \\
\hline $\begin{array}{l}\text { Argumentação } \\
\text { unilateral }\end{array}$ & $\begin{array}{l}\text { Assimétricos, em } \\
\text { desacordo e alinhados }\end{array}$ & Colaboração \\
\hline $\begin{array}{l}\text { Argumentação } \\
\text { unilateral aparente }\end{array}$ & $\begin{array}{l}\text { Assimétricos, em } \\
\text { desacordo e não alinha- } \\
\text { dos }\end{array}$ & Cooperação \\
\hline
\end{tabular}

Quadro 1: Classificação das subdimensões do modelo de Baker

\subsection{O papel dos scripts nas sessões colabora- tivas}

Um dos aspectos importantes para o funcionamento das sessões colaborativas é o planejamento. Para isso, Dillembourg [5] discute acerca dos scripts, isto é, os roteiros das sessões. O script é um documento que guia o mediador e os participantes antes e durante as sessões.

A estrutura dos scripts é composta por todos os aspectos relevantes à sessão, tais como: os softwares utilizados, o problema a ser investigado pelo grupo, as etapas da sessão e em alguns casos, o papel desempenhado pelo sujeito. Dessa forma, percebemos que o roteiro da sessão é um documento de extrema importância para que a interação seja bem sucedida e a escolha do modelo de script irá depender do objetivo e do ambiente escolhido pelo mediador. O autor destaca alguns modelos de scripts: o script induzido, o script de instrução, o script de treinamento, o script orientado e o "siga-me script". Em nossa pesquisa, utilizamos o modelo de Script de instrução. Nele o desenvolvedor da sessão deixa instruções, sejam orais ou escritas, de como proceder na colaboração e na solução da situação proposta. Dillemboug [5] argumenta que esse tipo de script pode ser mal interpretado e, em 
alguns casos, pode até não ser seguido pelos participantes afetando aquilo que foi proposto.

\section{Metodologia}

A proposta metodológica da pesquisa foi a análise do trabalho colaborativo dos licenciandos em Matemática quando submetidos a uma atividade de formação da elaboração de uma aula, fazendo uso do software Modellus na construção de simulações, na perspectiva da CSCL. Os estudantes trabalharam em grupos de até seis, escolhidos a partir da disponibilidade de cada um.

A atividade proposta se desenvolveu em cinco etapas: Listagem dos temas para discussão; Discussão com base nos temas listados; Elaboração da atividade, identificação dos objetivos de aprendizagem; montagem das etapas da atividade e detalhamento das atividades.

Apresentamos neste artigo a análise de um dos grupos, evidenciando os aspectos da colaboração identificados, como também os conhecimentos mobilizados na elaboração da aula pelo sujeitos. Denominamos o grupo de grupo Beta, constituído por três sujeitos todos licenciandos em Matemática, em fase de conclusão de curso, estudantes da disciplina de Prática de Ensino.

O grupo Beta participou da sessão em um horário diferente do da aula da disciplina. O encontro virtual ocorreu no sábado à tarde, horário disponibilizado pelo mediador. A sessão foi realizada da mesma maneira e obedecendo o mesmo limite de tempo, de $1 \mathrm{~h} 30 \mathrm{~min}$, que os outros sujeitos tiveram para construir a simulação e elaborar a atividade. Os registros coletados também foram derivados das mesmas fontes: áudio, chat e vídeo com ações na tela.

A escolha deste grupo neste artigo se deu pelos resultados em termos de colaboração encontrados em nossa pesquisa. O grupo Beta colaborou em todas as interações analisadas, sendo assim, levantamos aqui alguns dos aspectos mais relevantes que extraímos dos nossos resultados de pesquisa. Além dos aspectos da colaboração identificados, também fazemos um levantamento da articulação dos conhecimentos mobilizados pelo grupo: conhecimentos didáticos e matemáticos.

\subsection{O ambiente CSCL}

Estruturamos um ambiente de compartilhamento com softwares que permitissem a interação entre os sujeitos e a construção da aula proposta. O computador do mediador funcionou como um servidor, no qual foram instalados o software Teamviewer [6] e o Modellus [7], além de utilizar aplicativos do Google Drive [8] disponível online.
$\mathrm{O}$ ambiente em que se processou a atividade foi montado compartilhando os software mencionados, no intuito de promover a colaboração entre os sujeitos da sessão. Observe na figura 2 a estrutura do ambiente montado:
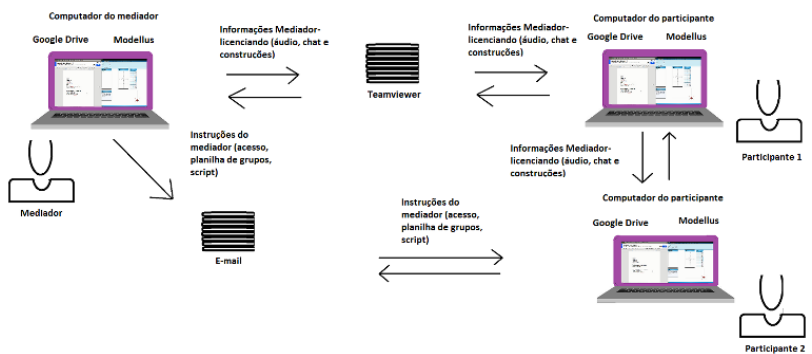

Figure 2: Estrutura do ambiente de compartilhamento

O Teamviewer é um software de controle remoto de informações, que permite ao usuário por acesso remoto visualizar tela de outro, bem como a manipulação das informações com o consentimento do outro (mediador da sessão). O software conta ainda com ferramentas de chat e áudio, permitindo a comunicação síncrona entre os sujeitos, e a gravação da sessão. Para uso pessoal, o software permite o acesso de até 15 pessoas por sessão de forma livre.

O Modellus, por sua vez, é um software de modelagem matemática, que permite a construção de simulações por meio de representações algébricas. O software é gratuito e o usuário pode manipular as representações algébrica, gráfica, escrita e tabular. As simulações construídas no Modellus permitem ao usuário, manipular as informações diretamente nas imagens, assim como nas variáveis do modelo.

Quanto ao Google Drive, fizemos uso das ferramentas de planilha - na montagem dos grupos - e documento para descrever os objetivos da aula, os tópicos da discussão e a atividade a ser elaborada.

\subsection{Montagem do Script}

A estrutura do script foi montada de acordo com a literatura [5]. Na montagem do roteiro contemplamos aspectos relativos à sessão como: os softwares utilizados; os objetivos e etapas da atividade; e uma instrução de instrumentalização com tutoriais e vídeos dos softwares necessários para a sessão.

Um documento com estas informações foi enviado aos licenciandos por e-mail anteriormente. Solicitamos aos participantes a leitura prévia do script, pois a apropriação das informações seria necessária para uma participação mais eficiente durante as sessões.

\subsection{Coleta dos dados}

Durante as sessões, gravamos as ações dos sujeitos na 
tela do mediador, arquivamos as sessões de chat e gravamos o áudio. A gravação do áudio, isto é, os dispositivos de som do ambiente foram realizadas com um gravador externo, pois não conseguimos coletar o áudio apenas com o software de gravação de vídeo.

A gravação de vídeo foi realizada com o software Camtasia em alguns momentos e em outros, utilizamos o dispositivo de gravação do próprio Teamviewer. Já as sessões de chat foram arquivadas no próprio Teamviewer, que permite ao mediador a coleta dessas informações ao fim de cada sessão. No caso do grupo Beta, foco deste artigo tivemos os seguintes dados:

- 2 textos sobre dificuldades e a atividade construídos no GDrive;

- 1 h45min de vídeo de captura de tela;

- 178 falas de chat.

Após a coleta, fizemos a categorização e análise dos dados. As falas do chat e com base no vídeo, identificações as conversas, denominação que demos a cada conjunto de falas e ações na tela que tinham um único objetivo. Nas sessões de análise apresentaremos as categorias, juntamente com as análises.

\section{Atividades do Grupo Beta}

Nesta seção, vamos fazer a análise dos dados em termos de colaboração, ambiente colaborativo (entraves e potencialidades), etapas de elaboração da atividade e os conhecimentos que foram mobilizados.

\begin{tabular}{|l|l|}
\hline \multicolumn{1}{|c|}{ Etapa } & \multicolumn{1}{c|}{ Conversa } \\
\hline $\begin{array}{l}\text { Listagem dos temas para } \\
\text { discussão }\end{array}$ & Familiarização \\
\hline $\begin{array}{l}\text { Discussão com base nos } \\
\text { temas listados }\end{array}$ & $\begin{array}{l}\text { Discussão sobre variáveis } \\
\text { na aprendizagem de fun- } \\
\text { ções }\end{array}$ \\
\cline { 2 - 2 } & Funções e Modelagem \\
\hline $\begin{array}{l}\text { Elaboração da atividade, } \\
\text { identificação dos objetivos } \\
\text { de aprendizagem; monta- } \\
\text { gem das etapas da atividade } \\
\text { e detalhamento das ativida- } \\
\text { des }\end{array}$ & Elaboração da atividade \\
\hline
\end{tabular}

Quadro 1: Conversas do Grupo Beta

Familiarização: esta conversa é composta por registros contendo falas do mediador e de dois participantes da sessão. Nela, são esclarecidos alguns aspectos do script para ajudar os participantes, no início da discussão. Além disso, também são identificados alguns entraves de áudio que serão descritos adiante.
Discussão sobre variáveis na aprendizagem de funções: esta conversa marca o início da discussão sobre a elaboração da atividade. Identificamos nesta conversa, a preocupação dos sujeitos com a dificuldade dos estudantes em relação à compreensão do conceito de variável no contexto das funções. Alguns entraves tecnológicos são identificados.

Funções e Modelagem: nesta conversa o mediador inicia a discussão sobre as funções como modelo de situações. Os participantes discutem sobre isso colocando em evidência que a desvinculação do conteúdo escolar, com situações contendo funções como modelos podem contribuir na dificuldade de aprendizagem por parte dos estudantes.

Elaboração da atividade: esta conversa é caracterizada pelas ações dos participantes na construção da simulação.

\subsection{Aspectos da Colaboração do Grupo Beta}

Nesta seção iremos descrever a análise do grupo Beta. Vamos iniciar com a análise da colaboração (papel do sujeito e posicionamento), análise da dimensão alinhamento e depois uma abordagem de outros aspectos do ambiente colaborativo. Trazemos nos gráficos desta seção mais um tipo de sujeito que achamos pertinente: o participante não identificado. Levando em consideração os momentos em que algumas ações na tela não têm o autor identificado diretamente e nem por meio das outras fontes de dados.

\subsubsection{Conversa discussão sobre variáveis na aprendizagem de funções.}

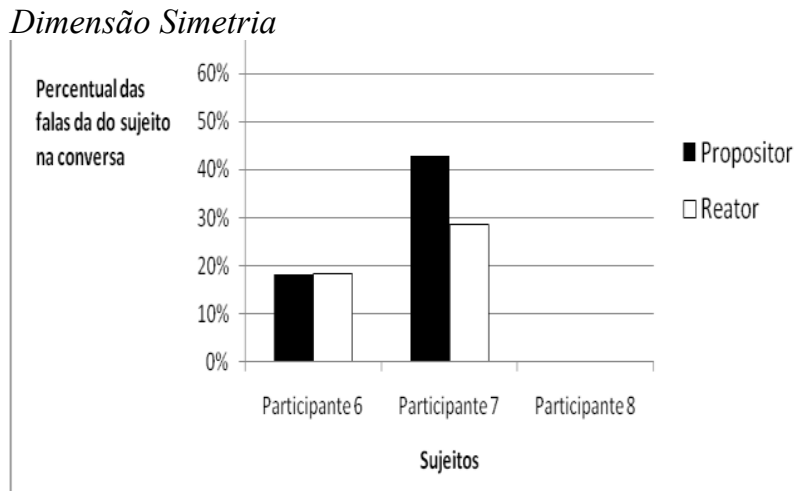

Gráfico 1: Distribuição das interações por participante segundo papel de propositor e reator na discussão sobre variáveis na aprendizagem de funções

Identificamos nesta conversa uma interação entre os participantes 6 e 7 com troca de papéis entre os sujeitos. O participante 7 se coloca mais como propositor, obtendo, em alguns casos, feedback do participante 6. Por 
outro lado, o participante 6 se posiciona como propositor em um percentual bem menor que o participante 7 . Nesta conversa, identificamos que ocorreram alguns entraves técnicos, que foram sendo solucionados com a ajuda do mediador. Esses entraves tomaram algum tempo da discussão entre os sujeitos que, mesmo assim, conseguiram produzir ideias para a próxima etapa da sessão.

Podemos dizer que neste caso ocorreu a simetria, pois observamos uma troca de papéis entre os sujeitos - quem foi propositor também reagiu em alguns momentos e reciprocamente, os reatores também assumiram o papel de propositor-configurando esta simetria.

\section{Dimensão Acordo}

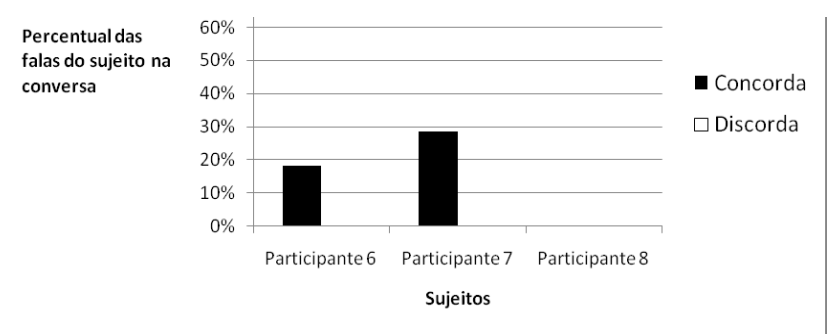

Gráfico 2: Distribuição das interações por participante segundo a dimensão acordo sobre variáveis na aprendizagem de funções

Uma comparação dos gráficos 1 e 2 mostra que o percentual das falas de concordância dos participantes é igual ao percentual das falas de reação. Isso significa que temos um caso de acordo entre os participantes 6 e 7 e que este grau de acordo é alto. Levando em consideração que se um foi propositor do outro, quer dizer que a reação obteve feedbacks positivos.

\section{Dimensão Alinhamento}

Selecionamos trechos da interação na discussão sobre variáveis na aprendizagem de funções para analisar o alinhamento.

Linhas 18 - 22

L 18 Participante 7 (15:14): eu acho que uma das grandes dificuldades quando começamos a ensinar funções é que os alunos geralmente confundem funções de variáveis com expressões algébricas.

L 19 Participante 6 (15:15): é verdade...

L 20 Participante 7 (15:15): principalmente se é dado algum x para eles calcularem $f(x)$ esse é um exercício de fixação muito comum, mas dai eles podem não compreender o que seja variável

L 21 Participante 6 (15:16): exatamente. Me parece que a ideia de variável é um obstáculo incialmente.

L 22 Participante 7 (15:17): é, talvez o maior obstáculo pois a idéia é que ele entenda que é uma relação de um conjunto em outro. Podendo ambos serem infi- nitos. então nada garante que y assumirá valores fixos.

Identificamos neste trecho da conversa a preocupação dos participantes em esclarecer para o estudante a diferença entre variável e incógnita. Na literatura em ensino e aprendizagem de funções, algumas pesquisas [9] e [10] mostram a importância de distinguir as variáveis em funções com as incógnitas das equações.

Notamos também que a interação nesta conversa ocorre entre dois participantes e que não há uma divisão de tarefas, nem um desvio no tema da conversa. Neste caso, a conversa está alinhada e os participantes debatem acerca do que foi proposto no script, ou seja, discutir sobre as dificuldades de aprendizagem dos estudantes.

\subsubsection{Conversa Funções e Modelagem}

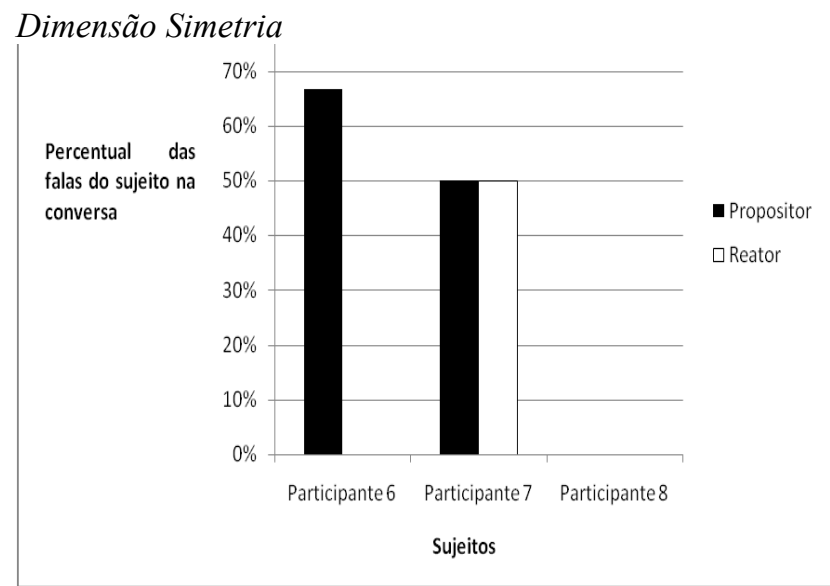

Gráfico 3: Distribuição das interações por participante segundo papel de propositor e reator na conversa Funções e Modelagem

Na segunda conversa que envolve aspectos da colaboração, percebemos que os papéis dos sujeitos não é alternado como na conversa anterior. Percebemos aqui que o participante 6 aparece com um percentual de propositor mais alto que o participante 7 , mostrando que nesta conversa houve bastante sugestões de sua parte. Em contrapartida, o participante 7 permanece como propositor e reator, sem que haja feedbacks do participante 6 para as suas colocações. Neste caso, consideramos uma assimetria na interação. Nesta conversa o mediador aparece guiando os participantes na interação, sugerindo aspectos a serem considerados e controlando as ações, para que os sujeitos não se dispersem na fase seguinte. 


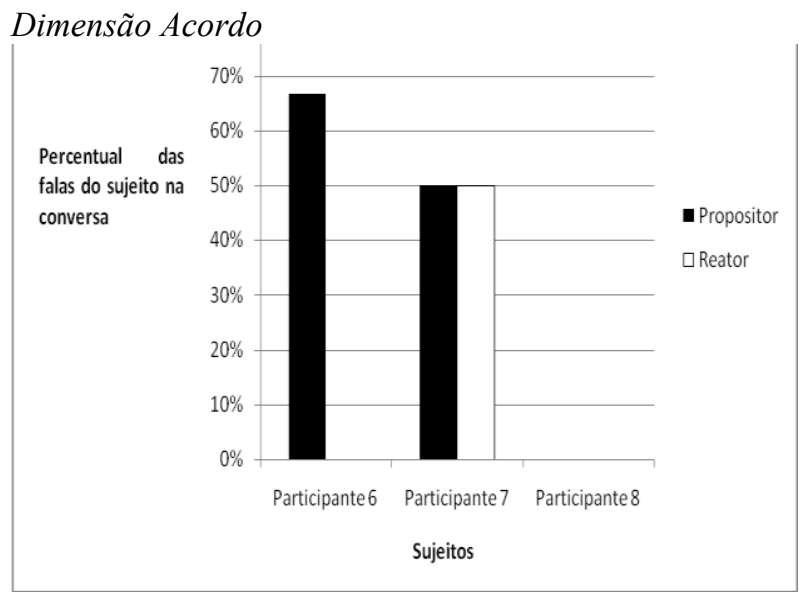

Gráfico 4: Distribuição das interações por participante segundo a dimensão acordo sobre Funções e Modelagem

Como tivemos apenas um reator na conversa, podemos concluir pelo percentual do gráfico acima, que a interação nesta conversa esteve em acordo.

\section{Dimensão Alinhamento}

\section{23 Participante 6 (15:18): o software conge-}

lou...estou de volta.

L 24 Mediador (15:18): pensando por esse lado de confusão entre função e expressão algébrica ou mesmo, para entender o conceito de variável, vamos pensar na perspectiva da modelagem matemática. Será que eles conseguem ver as funções como algo prático?

L 25 Participante 6 (15:20): essa discusão é complicada. o "prático" para um indivíduo pode não ser para outro.

L 26 Mediador (15:21): digo prático, no sentido de ser aplicado na realidade em que ele vivencia. Será que os estudantes conseguem perceber, que as funções modelam situações reais?

L 27 Participante 6 (15:21): mas é possivel fazer exposições desse conteúdo mostrando exemplos de utilização fora do contexto escolar.

L 28 Participante 7 (15:21): se os professores abordarem funções apenas do ponto de vista matemático sem contextualizar pode ficar dificil. Se eles aprendem apenas a calcular funções não significa que eles entendem de fato o conceito de funções.

L 29 Mediador (15:23): Vocês conseguem pensar em algo para a atividade, se guiando por estes elementos, colocados por vocÊs aqui?

L 30 Participante 6 (15:25): essa discusão de contextualização também é interessante.

Observamos aqui que os participantes são instigados pelo mediador a debater sobre as funções como modelos. Percebemos que os participantes concordam com o mediador sobre a importância da contextualização na escola. E são utilizados argumentos para defender esta ideia. $\mathrm{Na}$ fala da participante 7 , percebemos que ela deixa claro que as situações quando contextualizadas, contribuem no processo de compreensão do conceito. As ideias aqui colocadas mostram a necessidade de dar significado ao objeto matemático.

Sierpinska [11], outra importante pesquisa da literatura de ensino e aprendizagem de funções, discute que as funções são vistas como objetos que não pertencem ao mundo real, ou seja, não possuem significado algum para os estudantes. Por outro lado, se esta abordagem for realizada na perspectiva da modelagem, a compreensão do objeto como algo que modela fenômenos possibilita ao estudante perceber que se trata de algo próximo da sua realidade. Isto parece ocorrer com o conhecimento do grupo Beta sobre ensino e aprendizagem de função.

Sendo assim, esta conversa também se configura como alinhada já que os participantes se encontram na mesma base semântica e não há divisões na interação.

\subsubsection{Conversa Elaboração da Atividade}

Dimensão simetria

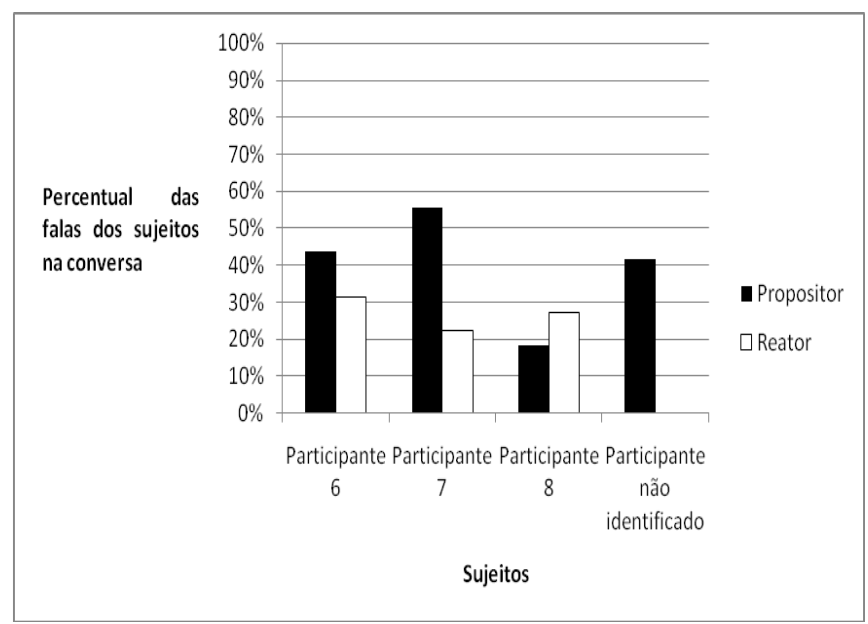

Gráfico 5: Distribuição percentual das interações por participante segundo papel de propositor e reator na Elaboração da Atividade

Esta conversa é a última deste grupo e a que gerou mais interação entre os usuários. Podemos perceber no gráfico que todos os sujeitos estão presentes nesta etapa de elaboração da atividade. $O$ participante 8 não entrou na sessão anteriormente por não ter conseguido o ID da sessão, já que seu nome não constava na lista de participantes do grupo na planilha. Já o participante não identificado, aparece nesta fase já que nela estão concentradas as ações em vídeo que não conseguimos identificar de 
quem são por meio das fontes de dados. A entrevista realizada com o grupo anterior não foi realizada com este grupo, pois nenhum participante foi localizado depois da sessão.

Retomando o aspecto de papel do sujeito na colaboração, vemos no gráfico que o percentual de interação nesta conversa é alto e, além disso, vemos a participação de todos os sujeitos. A troca de papeis entre eles ocorre, mesmo com uma diferença de percentual reator - propositor, vemos que há uma alternância de papeis o que configura uma interação simétrica.

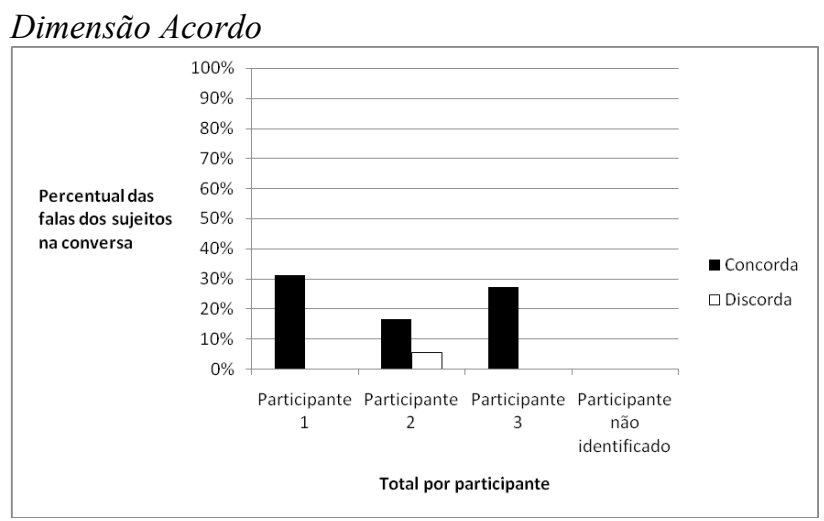

Gráfico 6: Distribuição percentual das interações por participante segundo o posicionamento de concordância ou discordância na Elaboração da Atividade

No aspecto da colaboração que corresponde ao posicionamento do sujeito, notamos que há um alto percentual de concordância. Diante das colocações dos colegas, observamos um posicionamento favorável às ações uns dos outros. A elaboração da atividade foi construída por esses sujeitos com uma compreensão mútua, que pode ser percebida nos percentuais de acordo que vemos no gráfico.

\section{Dimensão Alinhamento}

$\mathrm{Na}$ análise da dimensão de alinhamento, destacamos da conversa um longo trecho subdividido em três momentos distintos da interação. Primeiro, há uma delimitação do problema a ser criado, quando os participantes 6 e 7 conseguem definir um público específico para aplicar a atividade.

Linhas 133 - 161

L 134 Participante 7 (15:58):Participante 6?

L 135 Participante 6 (15:58): http://bit.profmatsbm.org.br/xmlui/handle/123456789/419

L 136 Vídeo:o navegador Internet Explorer é aberto na página do mestrado profissional em Matemática (PROFMAT - UFRN) em uma dissertação, intitulada: $\mathrm{O}$ estudo das funções quadráticas e sua relação com o cotidiano.

\section{137 Participante 7 (15:58): Já abri aqui}

L 138 Participante 7 (16:01): Abre aí o capitulo que
estás falando

Em seguida, o participante 8 entra na sessão e os três começam a discutir a criação do problema, a partir de uma texto indicado pelo participante 6 .

\section{139 Participante 8 (16:01): CERTO Participante 6 ESTOU ANALISANDO}

L 140 Vídeo: o documento da dissertação é aberto e o sumário é visualizado.

L 141 Vídeo: são mostrados no documento algumas situações envolvendo funções quadráticas, lombadas, arcos de parábola em arquitetura de casas. Em seguida, é mostrada uma página que aborda algumas características da parábola graficamente e algebricamente, concavidade, ponto de mínimo e variação dos coeficientes.

L 142 Participante 7 (16:06): Bem, esse problema com lombadas é interessante

L 143 Participante 8 (16:07): A PROPOSTA É BOA L 144 Participante 7 (16:09): Uma lombada pode ser descrita, pelo menos do ponto de vista planar lateral como uma secção do gráfico de uma parábola, se ela estiver centrada no $x=0$ o ponto de máximo da parábola é a altura y da lombada

L 146 Participante 8 (16:11): O COMPRIMENTO DELA QUE DIZESSES SEIA O QUE ESTÁ REPRESENTADO NO EIXO X, NÃO O SEU ARCO CERTO?

L 150 Participante 7 (16:14):Pensei nisso: Poderíamos contextualixar dizendo que uma pessoa em seu carro passou na velocidade permitida na lombada e o sistema de amortecimento do carro estava ok. então ele resouveu denunciar ao (órgão responsável pelas estradas) pois essa lombada estava desregular e foi muito impactante. então, como verificar que está anormal?

L 151 Participante 6 (16:15): pode ser...

L 152 Participante 7 (16:15): Mas vocês homens devem confirmar que a altura da lombada pode prejudicar o carro ? rsrs considerando que há uma velocidade permitida e que há uma função padrão para construção da lombada

L 153 Participante 6 (16:17): 1,50 $\mathrm{m}$ por $8 \mathrm{~cm}$ ou 3,70 m por $m c 011$

L 154 Participante 8 (16:17): É BOM ESCREVER Participante 6 POIS AS VEZES NAO TE ESCULTO $B E M$

L 155 Participante 7 (16:17): Ou seja, para tal velocidade teremos uma função padrão que determina a lombada. Então se a lombada estiver fora de tal função o dono do carro deverá ser idenizado L 157 Participante 7 (16:20): Qual equação.?Para a lomabda de $1 \mathrm{~m}$ por $20 \mathrm{~cm}$ o texto já tem uma solução. 
L 158 Participante 7 (16:21):Podemos usar a equação do problema da monografia como padrão.

L 159 Participante 8 (16:22): A QUESTÃO SUGERE CRIAR UMA EQUAÇÃO PARA LANÇAR NO MODELLUS?

Finalmente, há a escrita do problema no documento do Google Docs.

L 160 Vídeo: a página do docs é aberta novamente e começam a editar:

Ideia para o problema: determinar a função quadrática associada a uma lombada de $100 \mathrm{~cm}$ de comprimento e $20 \mathrm{~cm}$ de altura.

L 161 Vídeo: edição no docs:

Ao passar por uma lombada Roberto percebeu que o impacto no carro foi maior do que o esperado, ele verificou que estava na velocidade permitida e que o carro tinha sido revisado a pouco tempo, ou seja, o amortecimento do carro estava ok. Ciente que havia alguma irregularidade na lombada ele entrou em contato com o órgão responsável pelas vistorias na estrada. Ao chegar o suporte técnico ele informou que uma lombada padrão deve ter $20 \mathrm{~cm}$ de altura e $100 \mathrm{~cm}$ de comprimento e que a curva que representa a lombada pode ser escrita como uma função quadrática. Então, sabendo que a altura da lombada considerada irregular é de 25

\section{Linhas $164-178$}

L 164 Vídeo: um trecho do texto é modificado.

Deve ter $20 \mathrm{~cm}$ de altura e $100 \mathrm{~cm}$ de comprimento e que a curva que representa a lombada pode ser escrita como uma função quadrática é trocado por:

Deve ser representada pelo gráfico da função

L 165 Participante 6 (16:33): Uma lombada padrão tem $3,70 \mathrm{~m}$ por $10 \mathrm{~cm}$

L 166 Participante 7 (16:44):Pra mim está ok

L 167 Vídeo: Alguém tenta colar um texto e não consegue, sendo colado um texto indesejado.

L 168 Vídeo: Escrevem no docs: $\mathrm{f}(\mathrm{x})=-1|\||||||$

L 169 Vídeo: apaga-se as barras e é inserido: -

L 170 Vídeo: Alguém vai no menu "inserir" do docs e clica na opção inserir equação.

L 171 Vídeo: Há uma dificuldade em inserir a opção de fração.

L 172 Vídeo: Conseguem inserir a fração -1/125.

L 173 Vídeo: voltam para o texto do script e inserem a equação no editor do Word. A equação escrita é: $f(x)=-\frac{1}{125} x^{2}-20$.

No primeiro momento percebemos que há uma forte interação entre os participantes 6 e 7 na delimitação do problema. Entre as linhas 109 e 118 percebemos que eles trabalham juntos e pensam em um público específico para delimitar a escolha do problema. Em seguida, o participante 8 chega na discussão e toma parte na interação. Percebemos que há uma troca de informações entre todos, principalmente, quando o participante 6 sugere um link na L136. A partir disso, começam a discutir sobre aspectos didáticos e matemáticos antes de delimitar o problema a ser editado no Google Docs.

No último trecho não conseguimos identificar se há troca de ações na execução da edição no docs. Percebemos que os participantes após a discussão anterior, colocam no documento suas ideias e encontram algumas dificuldades quanto ao uso do recurso tecnológico. Classificamos esta interação como alinhada, pois os sujeitos estão em constante interação e constroem juntos a proposta da atividade. Apesar de não chegarem a executar a simulação, percebemos que este foi o grupo trocou mais informações e usou mais das ideias uns dos outros, para elaborar a atividade [12].

O Quadro 3 sintetiza e classifica as interações em cada conversa se classificam no modelo de Baker.

\begin{tabular}{|l|l|l|}
\hline \multirow{2}{*}{\multicolumn{1}{|c|}{ Conversa }} & \multicolumn{2}{|c|}{ Classificaçães } \\
\cline { 2 - 3 } & $\begin{array}{l}\text { Dimensões da cola- } \\
\text { boração }\end{array}$ & $\begin{array}{l}\text { Modelo de } \\
\text { Baker }\end{array}$ \\
\hline $\begin{array}{l}\text { Discussão sobre } \\
\text { variáveis na } \\
\text { aprendizagem de } \\
\text { funções }\end{array}$ & $\begin{array}{l}\text { Simétrica, em acordo } \\
\text { e alinhada. }\end{array}$ & Co-construção \\
\hline $\begin{array}{l}\text { Funções e Mo- } \\
\text { delagem }\end{array}$ & $\begin{array}{l}\text { Assimétrica, em acor- } \\
\text { do e alinhada. }\end{array}$ & $\begin{array}{l}\text { Co-elaboração } \\
\text { aquiescente. }\end{array}$ \\
\hline $\begin{array}{l}\text { Elaboração da } \\
\text { atividade }\end{array}$ & $\begin{array}{l}\text { Simétrica, em acordo } \\
\text { e alinhada. }\end{array}$ & Co-construção \\
\hline
\end{tabular}

Quadro 2: Classificação dos aspectos da colaboração no modelo de Baker - Grupo Beta

No modelo tridimensional de Baker observamos que as conversas discussão sobre variáveis e elaboração da atividade estão localizadas no círculo de número 1 (ver Figura 3). Observe que a posição deste número no cubo é favorável aos eixos das três dimensões, isto é, há acordo, simetria e alinhamento. Este esquema distribui as oito classificações de forma que cada uma assume sua posição no eixo tridimensional, exatamente como ocorre no espaço. A conversa funções e modelagem ocupa o mesmo espaço que as últimas conversas do grupo anterior. Perceba que ela se localiza na parte inferior do cubo, no círculo de número 5 , caracterizando-se como assimétrica, alinhada e em acordo. 


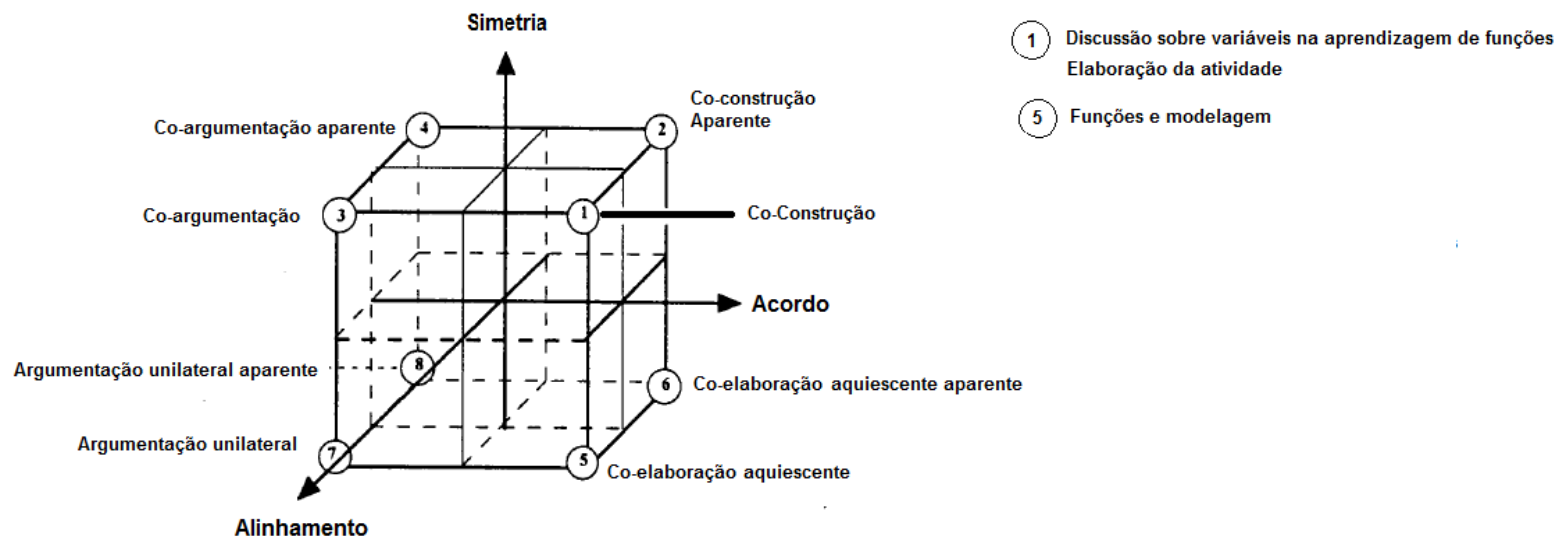

Figure 3: Esquema do modelo de Baker [3] adaptado - Grupo Beta

\subsection{Entraves nas Interações do Grupo Beta}

Nesta seção discutiremos os entraves identificados durante a sessão do grupo Beta. A análise contará com dados percentuais apresentados nos gráficos a seguir e, também, com comentários dos trechos onde são identificados os percentuais mais altos com relação aos entraves.

Também será apresentada nesta seção uma análise dos conhecimentos mobilizados por conversa, identificando os principais conhecimentos nos percentuais apresentados nos gráficos e também fazendo um comentário dos trechos nas conversas, onde esses conhecimentos aparecem.

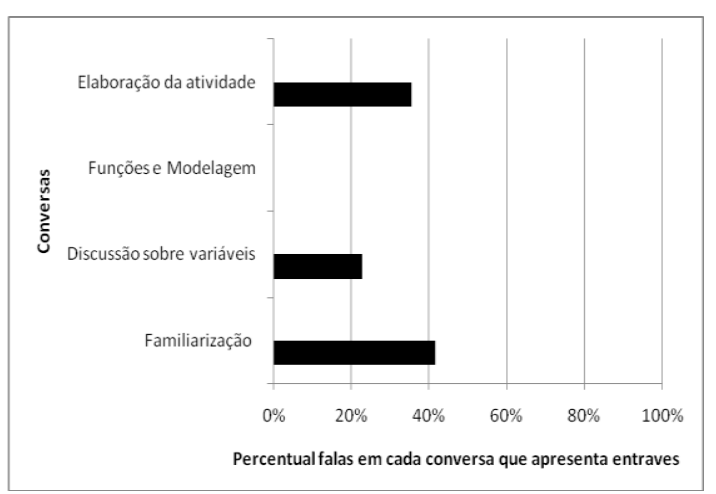

Gráfico 7: Distribuição percentual de falas que apresentam entraves em cada conversa

O Gráfico7 mostra o percentual de falas identificadas em cada conversa do grupo Beta que apresentam entraves. Na primeira conversa (familiarização) percebemos que há uma incidência maior de entraves. Na etapa de familiarização, os sujeitos ainda estavam se adaptando ao ambiente, acarretando alguns entraves que serão descritos adiante. A segunda conversa (discussão sobre variáveis) mostra um percentual menor de entraves, mas que foram identificados nas ações do participante 6. Essas ações consistiram em dificuldades de manter uma conexão no Teamviewer. O software suporta todos os tipos de sistemas operacionais, no entanto, percebemos que o participante 6 ao utilizar outro sistema diferente do Windows encontrou dificuldades em manter uma conexão instável. Essa informação foi fornecida pelo próprio participante, que destacou sua conexão à internet como normal, mas o seu sistema era diferente do que estava sendo utilizado pelos outros participantes.

$\mathrm{Na}$ terceira conversa (funções e modelagem) percebemos que não são identificadas falas que apresentam entraves. Nesta conversa os participantes 6 e 7 interagiram utilizando o chat e nenhum entrave foi identificado. Por outro lado, na última conversa (elaboração da atividade) temos um aumento no percentual de falas que apresentam entraves. Os entraves identificados nesta conversa foram provenientes, em sua maioria, de identificação do autor da ação.

Vamos mostrar agora o gráfico dos tipos de entrave identificados em cada conversa. Ele nos ajudará a compreender os trechos que serão analisados a seguir.

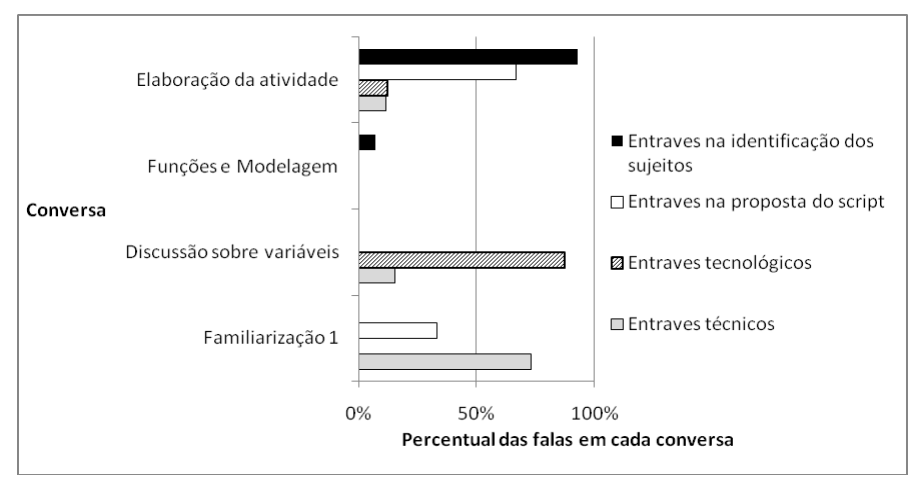

Gráfico 8: Distribuição percentual dos tipos de entraves por conversa 
Na conversa de familiarização percebemos que o percentual total de entraves divide-se em dois tipos de entraves: entraves técnicos e entraves na proposta do script. $\mathrm{Na}$ análise do grupo Beta percebemos que é comum aparecerem estes entraves devido às limitações do software de compartilhamento de tela, como também no esclarecimento de dúvidas dos participantes na proposta da construção da simulação. $\mathrm{O}$ estrato a seguir nos permite perceber tais entraves.

\section{1 Participante 7 (áudio): Participante 6?} L 2Participante 6 (áudio): Oi vamos para o chat que aqui está ruim de escutar.

L 3 Participante 7 (áudio): Ok. Estou indo pra lá. L 4 Participante 6 (áudio): Não identificado... pode repetir?

L 5 Mediador (áudio): Oi Participante 6? L 6 Participante 6 (áudio): Eu não consigo acessar o bate papo. Pode repetir a discussão?

L 7 Participante 6 (áudio): toda vez que eu tento conectar gera um usuário diferente e fica caindo a conexão.

L 8 Mediador (áudio): é... deve ser uma limitação da versão para MAC. O meu e o da Participante 7 está normal.

L 9 Participante 7 (áudio): é, no meu tá normal. L 10 Mediador (áudio): você consegue ver o bate papo?

L 11 Participante 6 (áudio): ainda não consigo ver.

L 12 Mediador (áudio): pera aí...

L 13 Mediador (áudio): e agora? Você consegue ver? Acabei de enviar uma mensagem.

L 14 Mediador (áudio): pronto, beleza! L 15 Mediador (áudio): o áudio também não está muito bom, mas não é só o seu não, o dela também.

L 16 Participante 6 (áudio): fica com ruído, repetindo a voz.

L 17 Mediador (áudio): é e também corta demais o áudio. Então acho que é um problema do software. Pode ser que tenha muita coisa aberta e não esteja suportando.

Na linha 6 (L6) percebemos que o participante 6 atenta para o entrave da conexão ou do uso do software de compartilhamento de tela. Perceba que ele diz que toda vez que entra, o software gera um usuário diferente, ou seja, o software indica aos outros participantes que há outra pessoa online, sendo que o usuário já entrou novamente com outro login. Além disso, percebemos que há uma reclamação do participante quanto ao áudio. Nesta sessão tivemos alguns problemas como ruídos, interferências, repetição da voz, que depois foram desaparecendo.
Alguns desses entraves de áudio estão relacionados ao ambiente no qual o participante se encontra. Ao se utilizar o áudio nesse tipo de sessão, sem dispositivos de headphone apropriado, termina-se por ampliar o espaço geográfico da sala de aula virtual, incluindo todo o som do ambiente em que os participantes se encontram.

Na conversa de discussão sobre variáveis identificamos entraves, denominados por nós de tecnológicos, mobilizados pelo participante 6 . Percebemos que o sistema operacional utilizado pelo participante causou muitos entraves no software de compartilhamento de tela. A conexão do participante 6 caiu constantemente durante esta conversa, sendo necessário a inserção do ID novamente e a retomada das discussões.

A elaboração da atividade aparece com um alto percentual de entrave na identificação dos participantes e na proposta do script. Como já colocamos anteriormente as ações em vídeo, na maioria das vezes, não puderam identificar qual participante executava. Quanto a proposta do scripts entraves surgiram por parte do Participante 8, que entrou nesta fase da sessão e não estava a par da discussão inicial.

\subsection{Conhecimentos Mobilizados}

Além disso, percebemos também que os sujeitos articularam conhecimentos sobre as funções. A ideia da variável como um obstáculo na aprendizagem é apresentada na discussão, mostrando que os estudantes confundem a variável " $x$ ", em funções, com a incógnita " $x$ ", nas equações. Eles discutem ainda que os estudantes não compreendem que a função é uma relação de dependência e explicitam que esta relação ocorre de um conjunto para o outro.

A conversa seguinte "Funções e modelagem" apresenta um direcionamento do mediador para que os participantes da sessão iniciem uma nova discussão. Analogamente a conversa anterior, o mediador conduz os sujeitos para discutir sobre a contextualização no processo de aprendizagem. A discussão continua com a intervenção do mediador, ou seja, os participantes foram discutindo com base nas colocações dele, o que não ocorreu na conversa anterior.

Percebemos que neste caso houve assimetria, uma vez que, o participante 6 se colocou apenas como reator propositor. Por outro lado, o participante 7 alternou esses papeis, mas identificamos na análise que a conversa se classifica como assimétrica. Apesar da assimetria, a conversa esteve em acordo e alinhada, sendo classificada no modelo de Baker como colaborativa.

Quanto aos conhecimentos mobilizados pelos sujeitos, a discussão traz uma preocupação distinta da conversa 
anterior, passando do aspecto epistemológico para o didático. A conversa estava voltada para o uso de situações reais no ensino de funções. Os sujeitos argumentaram que esta abordagem é necessária para compreensão do conceito, sendo importante conectar os conteúdos escolares, com situações cotidianas.

Além disso, percebemos um fator cognitivo, evidenciado pelo participante 7: "Se eles aprendem apenas a calcular funções não significa que eles entendem de fato o conceito de funções". Perceba que o sujeito acredita ser necessária uma compreensão do conceito, que nem sempre ocorre, devido ao estudante saber calcular com precisão. No entanto, esse fator não mostra a verdadeira essência do conceito, pois o cálculo mecânico não permite ao estudante identificar o conteúdo, quando é apresentado dentro de um contexto específico.

A última conversa, "Elaboração da atividade", assim como a primeira conversa, não apresenta uma intervenção do mediador no processo de discussão. Nesta conversa também temos a presença do participante 8 que chega para articular junto aos colegas, na construção da atividade.

A construção da atividade do grupo Beta partiu não somente da discussão gerada anteriormente, mas pelas interações dos sujeitos ao longo do processo. Esta etapa se inicia com uma pesquisa de um material de suporte, para ajudar na elaboração de uma atividade mais elaborada. O participante 7 pesquisa uma dissertação de mestrado e compartilha com os colegas para discutirem como inserir o problema dentro de um contexto específico. Para isso, os sujeitos definem no documento compartilhado o público-alvo, os objetivos da atividade e o conteúdo a ser explorado, posteriormente, pesquisam no material uma situação adequada ao que traçaram no documento.

Todo este processo de elaboração se dá por meio da discussão entre os participantes, sempre procurando chegar a um consenso, eles dividem-se apenas para escrever as ideias já que o ambiente não permite ações mobilizadas por dois ou mais sujeitos ao mesmo tempo. O planejamento do grupo Beta contribuiu efetivamente para que o grupo colaborasse, além disso, o número reduzido de sujeitos permitiu uma melhor articulação dentro do ambiente montado.

\begin{tabular}{ll}
\hline Conhecimento mobilizado & \multicolumn{1}{c}{ Conceito } \\
\hline \multirow{2}{*}{ Didático } & $\begin{array}{l}\text { Planejamento: objetivos } \\
\text { traçados, escolha do conte- } \\
\text { údo, pesquisa do material. }\end{array}$ \\
& Ponto de máximo, altura, \\
Matemático & secção, comprimento.
\end{tabular}

Quadro 3: Conhecimentos mobilizados na elaboração da aula
Esta etapa de elaboração mobilizou os sujeitos a articularem vários tipos de conhecimento. Identificamos que o conhecimento didático foi bem evidente, tendo em vista as ações de planejamento mobilizadas pelos participantes, levando em consideração os objetivos traçados. Também identificamos na conversa uma discussão de teor matemático, quando os participantes começam a definir o modelo matemático para construção de uma lombada, apresentamos a seguir um quadro que mostra os conhecimentos mobilizados nesta conversa.

\section{Considerações Finais}

As análises do grupo Beta mostram alguns fatores importantes, que fizeram o grupo colaborar, além da mobilização de conhecimentos envolvidos no processo de interação.

A primeira conversa do grupo Beta, "Discussão sobre variáveis na aprendizagem de funções", traz a interação de dois sujeitos que discutem por meio do chat sobre a importância da compreensão do conceito de variável. Analisando os aspectos da colaboração nesse grupo, podemos destacar que a orientação do mediador, não foi necessária para que os sujeitos iniciassem a discussão. A apropriação do problema, isto é, a etapa de discussão para elaborar a aula, foi uma iniciativa dos sujeitos que por meio do script compreenderam a proposta do mediador.

A partir da discussão percebemos que as dimensões simetria, acordo e alinhamento são identificadas na interação. Os sujeitos articulam a conversa trocando os papeis de propositor e reator (simetria), além da concordância total do reator com relação às colocações do propositor (acordo). O alinhamento também ocorre, tendo em vista que há um engajamento dos sujeitos na conversa, sem haver dispersão do foco e falta de articulação por parte dos envolvidos.

Podemos afirmar a partir das informações apresentadas que o grupo Beta traz aspectos próprios que o define como colaborativo. Primeiro, o número de licenciandos deste grupo é menor se comparado aos outros grupos que também participaram do experimento. Segundo, o grupo Beta demonstrou uma autonomia maior, sem necessitar de intervenções constantes do mediador. E, finalmente, sua autonomia implicou em um planejamento detalhado na elaboração da aula, fazendo-o chegar a uma atividade bem elaborada.

O grupo Beta foi o único que não chegou à etapa de construção da simulação proposta no script. Esta informação nos faz refletir sobre as ações do grupo Beta durante a sessão, pois estas ações (mencionadas no parágra- 
fo anterior) demandaram mais tempo, uma preparação maior, que não ocorreu nos outros grupos.

\section{Referências}

[1] R.M. Araújo Filho. Análise da Colaboração em Situação de Formação de Professores de Matemática Online. Dissertação de mestrado do Programa de Pós-graduação em Educação Matemática e Tecnológica. 159f. Universidade Federal de Pernambuco. Recife,2015.

[2] G. Stahl, T. Koschmann, D. Suthers. ComputerSupported Collaborative Learning: an historical perspective. In R. K. Sawyer (Ed.) Cambridge handbook of the learning sciences. Cambridge. páginas 409-426, 2006.

[3] G. Stahl. Contributions to a theoretical framework for CSCL. In G.Stahl Computer support for collaborative learning: Foundations for a CSCL community. Proceeds of CSCL, páginas 62-71, 2002 .

[4] M. Baker. Forms of cooperation in dyadic problem-solving. Revue d'intellingence Arttificielle. 16:587-620, 2002.

[5] P. Dillenbourg. Over-scripting CSCL: The risks of blending collaborative learning with instructional design. In. P. A. Kirschnner (Ed). Three worlds in of CSCL: Can we support CSCL?. Heerlen, Open Universiteit Nerderland. páginas 61-91, 2002.

[6] GmBH TEAMVIEWER. TeamViewer software, 2005.

[7] V. Teodoro; J.P.Vieira; F.C.Clérigo. Modellus, interactive modelling with mathematics. San Mateo, CA: Knowledge Revolution, 1997.

[8] Google. Google Drive. Califórnia, 2012.

[9] M. Bakar, D.Tall. Student's mental prototypes for functions and graphs. In: Furinghetti (Ed.), Proceedings of the 15th International Conference for the PME. Assisti - Itália,. V. 1, pp. 104$111,1992$.

[10] I. Elia, P.Spyrou. How students conceive function: a triarchic conceptual-semiotic model of the understanding of a complex concept. The Montana Mathematics Enthusiast, Missoula, v. 3, n. 2, p. 256-272, 2006.
[11] A. Sierpinska. On understanding the notion of function. In: G. Harel e Ed Dubinsky (Eds.). The Concept of Function: Aspects of Epistemology and Pedagogy. MAA Notes. V25, p. 25 - 58. 1992. 